No. 19-6

\title{
Measuring Household Wealth in the Panel Study of Income Dynamics: The Role of Retirement Assets
}

\section{Daniel Cooper, Karen Dynan, and Hannah Rhodenhiser}

\begin{abstract}
:
While the Panel Study of Income Dynamics (PSID) has much to offer researchers studying household behavior, one limitation is that its summary measure of wealth is not as broad as those of other commonly used surveys, such as the Survey of Consumer Finances (SCF), because it does not include the value of defined-contribution (DC) pensions. This paper describes the pension data available in the PSID and shows how they can be used to create a more comprehensive picture of household finances. We then compare various measures derived from these data with their counterparts from the SCF. Along a number of dimensions, the PSID data line up fairly well. Notably, an augmented summary measure of PSID wealth that includes the value of DC pensions is considerably closer to the SCF summary measure than to the standard measure for the median household. We conclude by presenting several examples of research areas where using a broader measure of wealth might be important.
\end{abstract}

\section{JEL Classifications: E21}

Keywords: household wealth, retirement assets, household survey data

Daniel Cooper is a senior economist and policy advisor in the research department at the Federal Reserve Bank of Boston; his email is Daniel.Cooper@bos.frb.org. Karen Dynan is a professor of the practice in the economics department at Harvard University and a visiting scholar in the Boston Fed research department; her email is kdynan@fas.harvard.edu. Hannah Rhodenhiser is a senior research assistant in the Boston Fed research department; her email is Hannah.Rhodenhiser@bos.frb.org.

The authors thank Charlie Brown, Brian Bucks, David Johnson, Kevin Moore, Robert Moffitt, Fabian Pfeffer, John Sabelhaus, and Frank Stafford for helpful comments and discussion.

This paper presents preliminary analysis and results intended to stimulate discussion and critical comment. The views expressed herein are those of the authors and do not indicate concurrence by the Federal Reserve Bank of Boston, the principals of the Board of Governors, or the Federal Reserve System.

This paper, which may be revised, is available on the website of the Federal Reserve Bank of Boston at http://www.bostonfed.org/economic/wp/index.htm.

This version: August 2019

https://doi.org/10.29412/res.wp.2019.06 


\section{Introduction}

Measuring household wealth well is central to research aimed at understanding household behavior. The two primary data sets that researchers use to analyze household-level wealth in the United States are the Panel Study of Income Dynamics (PSID) and the Survey of Consumer Finances (SCF) 1 The SCF is more commonly used due to the established high quality of its balance sheet data, including at the upper end of the wealth (and income) distribution. But, the SCF has some limitations when it comes to understanding household wealth dynamics, as it generally offers only cross-sectional data. The PSID represents an important complement to the SCF, because while it does not track the upper-end of the wealth and income distribution, it includes longitudinal data, enabling researchers to examine the evolution over time of wealth and financial well-being at the household level. Moreover, the SCF contains very limited information about household spending, whereas the PSID has fairly comprehensive expenditure data, making the PSID a better source for studying the relationship between household wealth and consumption.

A key question for researchers is how well the PSID measures household wealth. Earlier studies conclude that the PSID wealth data track SCF wealth data well for households other than those at the very top of the distribution (see, for example, Bosworth and Smart 2010; ;feffer et al. 2016). ? $^{2}$ These results are reassuring along some lines for researchers interested in the behavior of most households. But, these studies begin by conceptually aligning the PSID and SCF wealth measures before comparing them. Notably, these studies subtract the value of assets held in employerprovided DC retirement accounts, such as 401(k)s, from the SCF summary measure of net worth, because the PSID summary wealth measure does not include the value of any pensions. $3^{3}$ Thus, these comparison studies do not speak to the ability of the PSID to capture a broader measure of wealth that includes these assets.

\footnotetext{
${ }^{1}$ The Health and Retirement Study (HRS) also contains useful household wealth data, but it focuses on only the older segment of the US population.

${ }^{2}$ The PSID website provides tables showing wealth comparisons based on the Pfeffer et al. (2016) methodology. See https: / /psidonline.isr.umich.edu/Guide/Quality/DataComparisons.aspx.

${ }^{3}$ The summary wealth variables in the PSID do include the value of any assets held in individual retirement accounts (IRAs) as well as the value of any annuities.
} 
This conceptual difference between the SCF and PSID summary measures of wealth has not received a lot of attention. However, the exclusion of DC assets has become a more important issue, given that the share of assets held in DC retirement accounts has grown to be considerable for many households $4^{4}$ Data from the SCF underscore this point. Figure 1 shows medians by wave for the SCF summary measure of wealth and the SCF measure excluding the value of holdings in DC retirement accounts. The gap was not very large in the late 1980s and early 1990s, but it has widened over time, with the median of the summary measure now substantially greater than the median for the wealth measure that excludes DC retirement wealth.

Figure 1: Medians of SCF Wealth Measures

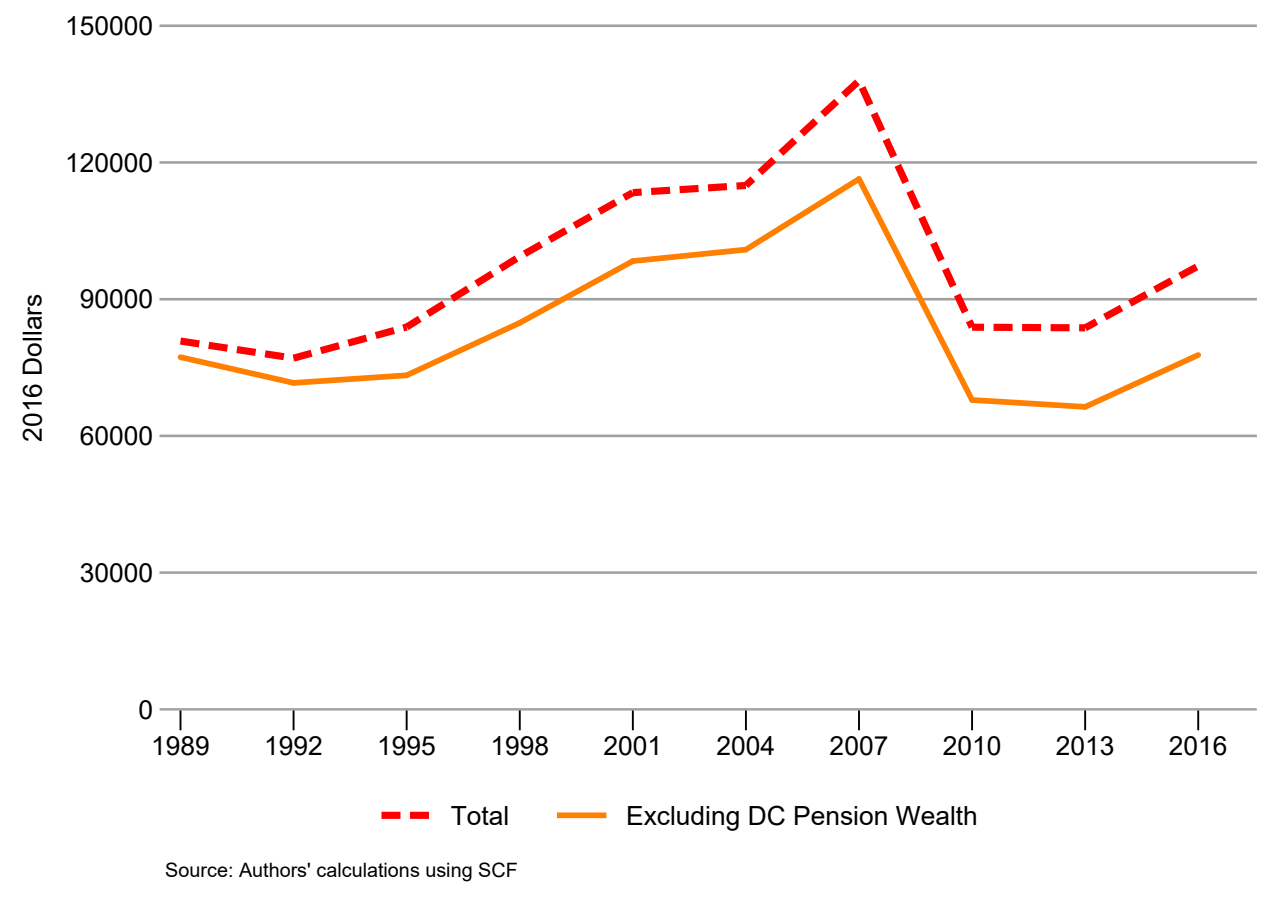

However, PSID researchers interested in more fully capturing household wealth should not overly despair about the lack of DC retirement wealth data in the PSID summary wealth measures, because substantial information about assets held through DC accounts is collected in the "pension module" of the PSID. This paper discusses these data and how researchers can use them to

\footnotetext{
${ }^{4}$ For the remainder of the paper we will refer to all 401(k)-type, DC, or "thrift" retirement accounts as DCs.
} 
calculate a more comprehensive measure of wealth for PSID households. 5 We show that the PSID information about DC wealth compares fairly well with that from the SCF, in terms of both the prevalence of DC accounts and the reported amount of wealth in these accounts.

We find that augmenting the PSID summary wealth measures with DC wealth substantially raises the estimate of household wealth for the typical household. Doing so also brings the measure much closer to the SCF summary wealth measure, as shown in Figure 2, Indeed, for the summary wealth measures that exclude home equity (essentially financial wealth), there is little difference between the augmented PSID measure and its SCF counterpart in recent years ${ }^{6}$ Related variables of interest to researchers, such as the share of PSID households who participate in the stock market, are also much closer to their SCF counterparts when information from the PSID pension module is included.

\footnotetext{
${ }^{5} \mathrm{~A}$ yet broader measure of household wealth would include the estimated value of households' Social Security and private defined-benefit (DB) wealth. See Sabelhaus and Volz (2019) for estimates of DB pension wealth for SCF households. We are not aware of any comparable work for the PSID. In any case, households probably do not view DB pension wealth as entirely the same as financial and non-financial wealth, so arguably it should be studied separately.

${ }^{6}$ The plots in Figure 2 are based on the standard wealth variables in the PSID and SCF for which missing data are assigned. We adjust the samples and use weights so that the reported data from both surveys should be representative of the US population. See Section 3 and the Appendix for further details about the data and sample criteria.
} 
Figure 2: Medians of Summary Wealth Measures
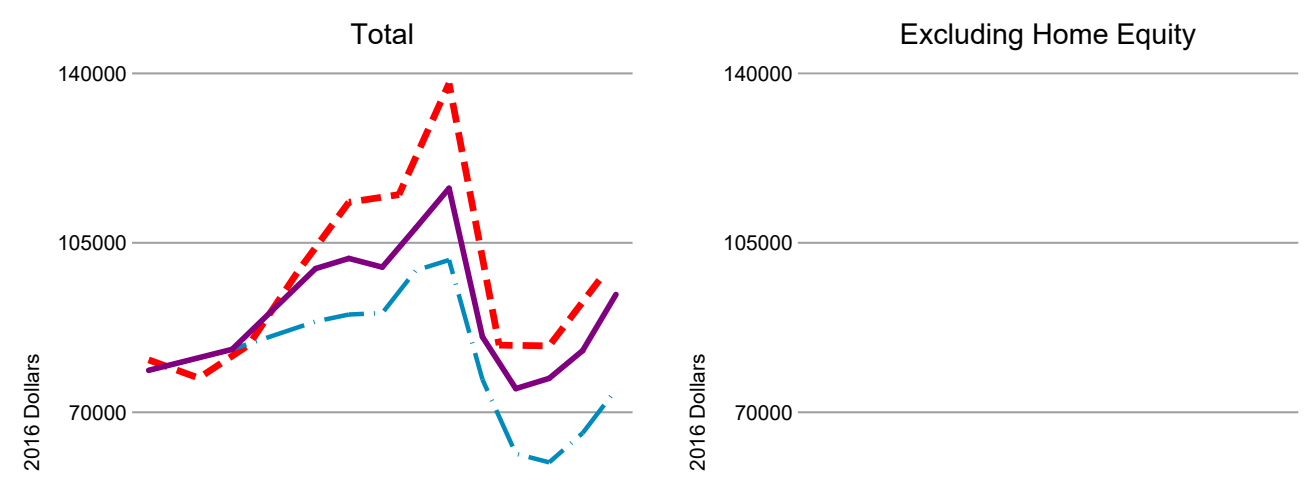

35000
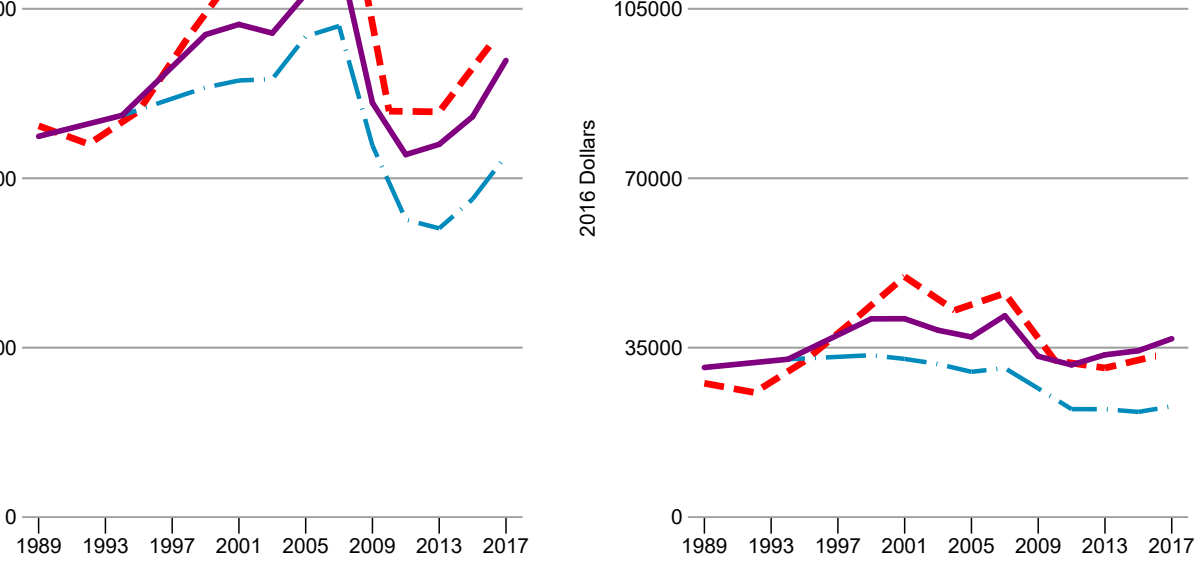

The remainder of the paper proceeds as follows. Section 2 discusses in more detail the PSID wealth data as well as the information about DC retirement accounts available through the PSID pension module. It goes on to document how these data can be used to estimate the value of assets held through DC pension accounts and, ultimately, to create a more comprehensive measure of wealth for PSID households. Section 3 evaluates how the new measures compare with information from the SCF. We conclude in Section 4 by highlighting several research areas where the PSID information about DC account holdings and the resulting more comprehensive measure of household wealth in the survey can potentially play an important role. 


\section{Measuring wealth and retirement assets in the PSID}

The PSID is a longitudinal survey for which households were interviewed annually through 1997 and since then have been interviewed biennially. The PSID began collecting wealth data every five years in 1984, but it has collected that data in every wave since 1999. The "wealth module" ("W" questions in the PSID questionnaire) tracks the value of eight separate components of household balance sheets: nonprimary real estate holdings, business equity (including farm equity), stocks (including mutual funds), bonds, vehicles, IRA/KEOGH accounts and annuities (IRAs), $!^{7}$ cash and/or bank account holdings, and nonhousing debt. Data on housing equity are calculated as households' (self-reported) home values (A20) minus their home mortgage debt (A24). All of these wealth components are combined, with missing values assigned when relevant, to generate the summary PSID wealth variables that are available to download from the PSID website. These variables are labeled "WEALTH1" and "WEALTH2" in the PSID codebook. WEALTH1 is imputed wealth excluding the value of equity in a household's primary residence, while WEALTH2 equals WEALTH1 plus any such housing equity.

Note that the IRA/KEOGH/annuity question in the wealth module does not ask about assets that households hold in employer-sponsored DC retirement accounts (though it would, in principle, pick up any DC holdings that have been rolled over into an IRA after a member of the household left a previous employer). Hence, WEALTH1 and WEALTH2 do not include the value of DC retirement accounts.

That said, the value of DC retirement assets in the PSID can be calculated using data from the pension module ("P" questions in the PSID questionnaire). Indeed, the PSID pension module data are quite detailed, tracking the values of the household head and spouse's (if applicable) retirement accounts at their current employers and at as many as two previous employers each. 8

\footnotetext{
${ }^{7}$ Before 1999, the value of households' IRA accounts was not tracked separately but rather was included as part of their stock market wealth.

${ }^{8}$ Current Employer: Questions P20 (head) and P20/P90 (spouse); there are two "P" variables listed for (any) spouse data, since where the data are recorded in the questionnaire depends on the year. For example, in some waves the spouse's current employer pension data are recorded under "P20" and in other survey years the same data are recorded as "P90."
} 
Previous employer accounts are tracked separately as "DC only" plans or the DC components of "hybrid" plans_-ones that have a defined-benefit (DB) part as well as a DC component 9 The survey distinguishes between money left in a DC retirement plan at a previous employer and money that is transferred into an IRA or other similar rollover-type account or is withdrawn.10 (Money that is withdrawn from retirement accounts at previous employers and is not spent shows up, at least in principle, as an increase in assets elsewhere on households' balance sheets.)

We use all of this information to create a summary measure of PSID wealth that includes DC retirement account wealth. To do so, we sum the DC account values for heads and spouses separately and then combine them to get a measure of overall DC wealth for the household (WPEN) ${ }^{11}$ We then add this amount to the WEALTH1 and WEALTH2 variables to obtain estimates of financial and total wealth, respectively, that each include DC account holdings.

One challenge is that many PSID households who report having DC retirement accounts from current or previous employers do not appear to know the exact value of their holdings in these accounts. In 2005, for example, about 30 percent of the households who reported having DC retirement accounts had missing account values. Since 1984, the PSID wealth module has allowed households who do not know exact amounts for specific types of wealth to instead report whether the amount fell into certain ranges; the pension module did not begin including a value range option for DC accounts until 2007: ${ }^{12}$ For the years when the value-range information is available, we use it to impute DC account values for households who were unable to offer an exact amount. We assign values equal to the midpoint of the reported range, except for the top bracket, which is unbounded. For those values, we use the (weighted) median value of DC accounts in the SCF

\footnotetext{
${ }^{9}$ Previous Employer: Hybrid: Questions P49 (head) and P49/P119 (spouse); DC only: P65 (head) and P65/P135 (spouse).

${ }^{10}$ Questions P48 and P64 (head) and P48/P118 and P64/P134 (spouse)

${ }^{11}$ In particular, we sum the reported values for questions P20, P49, and P65 for heads and P20/P90, P49/P119, and P65/P135 for spouses. (Recall that where the spouse data are recorded depends on the year. In addition, the previous employer questions [P49/P119 and P65/P135] track values for as many as two previous employers, which must be summed). In the 2017 wave, this corresponds to summing data in the following PSID mnemonics: ER68010 $+($ ER68051 + ER68131 $)+($ ER68111 + ER68191 $)$ for heads and ER68227 + (ER68268 + ER68348 $)+($ ER68328 + ER68408) for spouses.

${ }^{12}$ See questions P20B through P20E and P49B through P49E in the survey.
} 
over the same range ${ }^{13}$ In cases where we have no range data, we leave the DC account values as missing for households who report having an account but do not report a value.

Table 1: Importance of DC Account Imputations

\begin{tabular}{l|cc|cc}
\hline & $\begin{array}{l}\text { WPEN changed } \\
\text { with imputation }\end{array}$ & \multicolumn{2}{c}{$\begin{array}{c}\text { WPEN went from 0 } \\
\text { to positive value } \\
\text { with imputation }\end{array}$} \\
\cline { 2 - 5 } Year & $\mathrm{N}$ & $\%$ & $\mathrm{~N}$ & \% of Imputed \\
\hline 2007 & 178 & 12.13 & 129 & 72.47 \\
2009 & 192 & 14.24 & 141 & 73.44 \\
2011 & 110 & 7.44 & 80 & 72.73 \\
2013 & 130 & 8.30 & 96 & 73.85 \\
2015 & 116 & 7.29 & 84 & 72.41 \\
2017 & 163 & 9.45 & 125 & 76.69 \\
\hline Total & 889 & 9.69 & 655 & 73.68 \\
\hline
\end{tabular}

Each wave's share of households for whom we impute DC account values using this approach is material. The second and third columns of Table 1 show the number and percent of households with at least some imputed DC account value data in the 2007-2017 PSID waves. The counts are highest in 2007 and 2009, which were the first two waves that included the range questions, and was a period of great volatility in the stock market and the economy. In 2007 and 2009 we impute DC wealth information for 12 percent to 14 percent of PSID households with DC wealth, whereas in the 2011-2017 waves we impute data for only 7 percent to 10 percent of such households 14 Some households report actual values for some of their DC accounts (for example, the household head's current employer) but not all of them, so the imputation increases their existing (positive) WPEN amount. In contrast, other households report having a DC account or accounts but do not report the exact value for any of these account(s). For these households, WPEN goes from zero to a positive number after our imputation. The fourth and fifth columns of Table 1 show how

\footnotetext{
${ }^{13}$ In the 2017 PSID wave, this bracket corresponds to DC account values of $\$ 200,000$ or more. We use the SCF wave that was closest to the PSID survey year (2016 for the 2017 PSID wave) to assign a value to the bracket.

${ }^{14}$ We do not know if the higher shares in the first two waves reflect something about survey practices or whether they reflect the fact that households had more difficulty knowing their actual DC account values in 2007 and 2009 due to the high degree of both market and employment instability at the time.
} 
many households started with WPEN $=0$ but have positive account values (WPEN $>0)$ after our imputation. A large share of the additional wealth information generated from the imputation procedure is for households who otherwise would appear to have no DC pension wealth. For example, in 2007, 129 households out of 178 with imputed DC wealth data (72 percent) went from no value to a positive amount. These extensive margin gains meaningfully increase the share of households in our PSID sample with DC wealth data.

Figure 3: Median PSID DC Wealth for Households with Positive DC Wealth

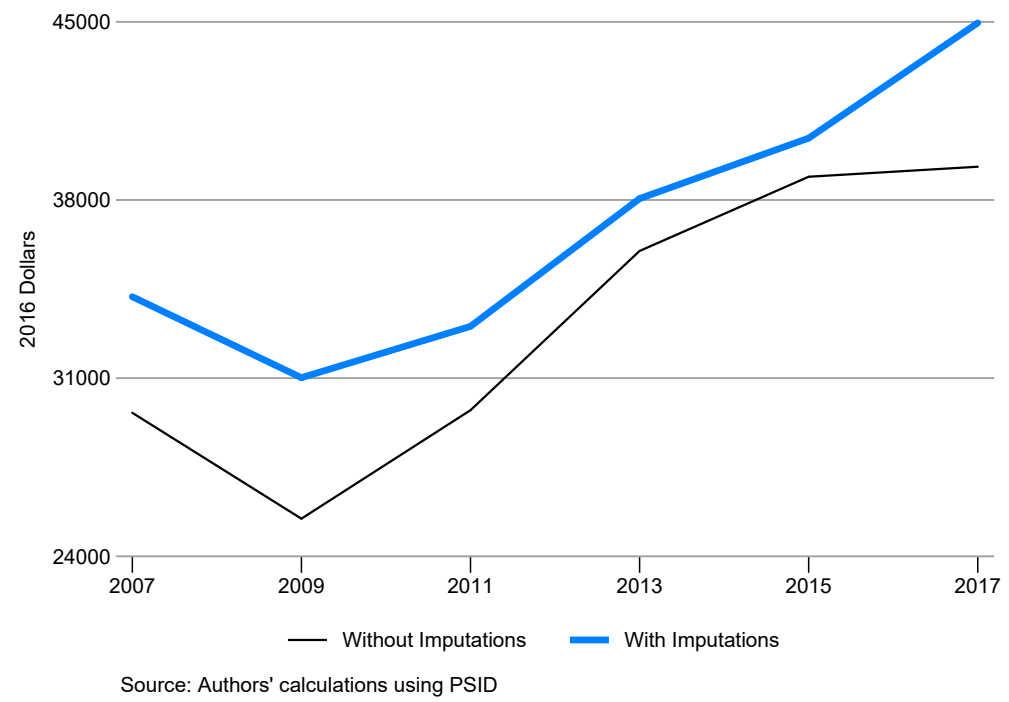

Figure 3 plots median DC wealth for households with WPEN $>0$. On average, from 2007 through 2017, the imputations raise the median level of DC wealth by 12 percentage points. Note that our imputation approach would not necessarily be expected to increase the conditional medians, since the underlying sample for the series including the imputed data is different—it incorporates households whose value of WPEN changed from zero to a positive amount. The imputed amounts for these households could have been small and pulled the median down.

Augmenting the information from the PSID wealth module with data from the pension module in this way also substantially increases the fraction of PSID households with retirement account assets. Figure 4 shows the share of households with retirement account wealth based on just the IRA information directly accessible in the wealth module and the share based on this information 
combined with data on DC account holdings from the pension module 15 The share based on the combined retirement wealth data is, on average, 20 percentage points higher than the share based on just the IRA/Keogh data. 16

Figure 4: Share of PSID Households with Retirement Accounts

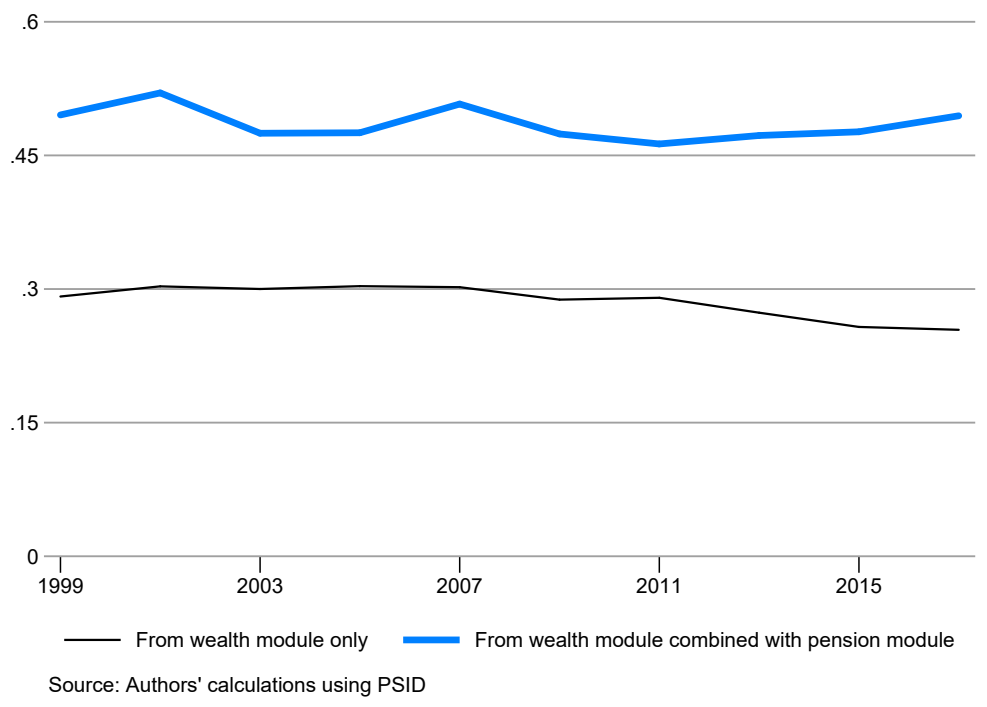

Figure 5 shows median values for household wealth augmented with DC account data (the PSID series from Figure 2). The left panel shows the regular and augmented series for overall wealth, and the right panel shows the same series for wealth excluding home equity. The augmented measures climb faster between the late 1980s and the mid-2000s and remain noticeably higher through 2017 (the most recent PSID wave).

\footnotetext{
${ }^{15}$ We count a household as having retirement savings if they report having at least one IRA or DC pension account, even if we do not have the range data we need to impute a missing DC account value.

${ }^{16}$ A similar pattern holds for the SCF. Including information about DC wealth raises the share of households with retirement accounts by an average of 21.6 percentage points from 1998 through 2016.
} 
Figure 5: Medians of PSID Wealth Measures

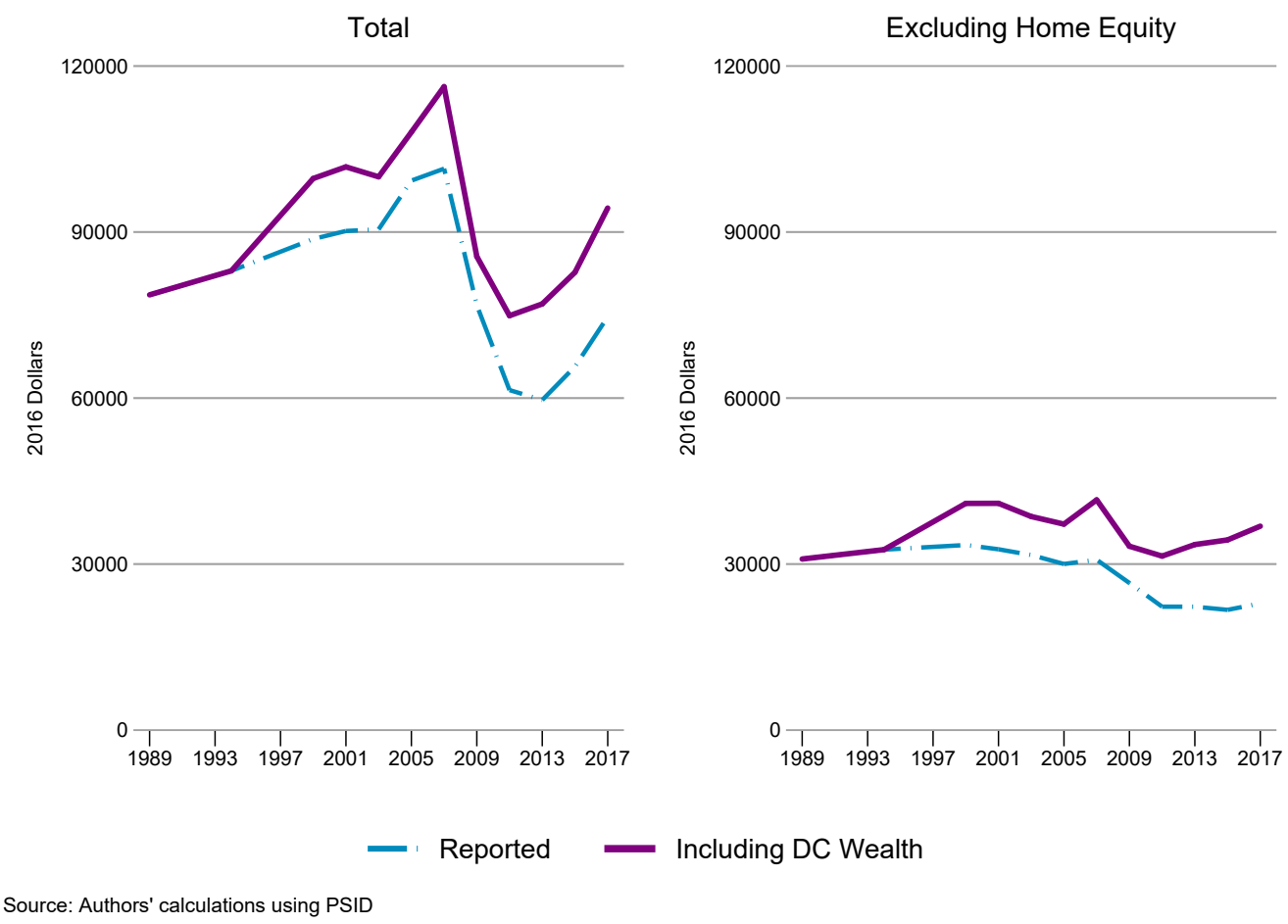

We also use the information from the PSID wealth and pension modules to estimate the value of stocks held (either directly or indirectly through mutual funds and other vehicles) by PSID households. To do so, we employ questions from the pension module asking how each DC account is invested; the response options are "mostly stocks," "mostly bonds," or a "mix." Based on these answers, we multiply the amounts in the DC accounts by 1,0 , or 0.5 , respectively, to estimate the value of stocks held in DC retirement accounts. ${ }^{17}$ We use the same approach to determine the value of stocks held in IRA accounts and add the resulting estimated DC account and IRA stock values to the value of households' stock holdings reported in the wealth module that are held in (taxable) brokerage-type accounts.

Not surprisingly, augmenting the data from the wealth module with data from the pension module substantially increases the share of PSID households who appear to be participating in the

\footnotetext{
${ }^{17}$ We follow the 50 percent approach the SCF uses when an account is reported as a "mix," and assume that "don't know" is also a mix of asset types. In addition, some households report DC account values but have missing data for the type of investments in those accounts. In these cases, we similarly assume a 50 percent stock holding.
} 
stock market ${ }^{18}$ As shown in Figure 6, the combined data imply that about 46 percent of PSID households are participating in the stock market, which is about 13 percentage points higher, on average, than the share implied by data in the wealth module alone (which includes stocks held directly, through mutual funds, and through IRAs). For the period over which we can impute missing DC account value data (2007-2017), the gains are even larger: about 16 percentage points on average.

Figure 6: Shares of PSID Households Participating in the Stock Market

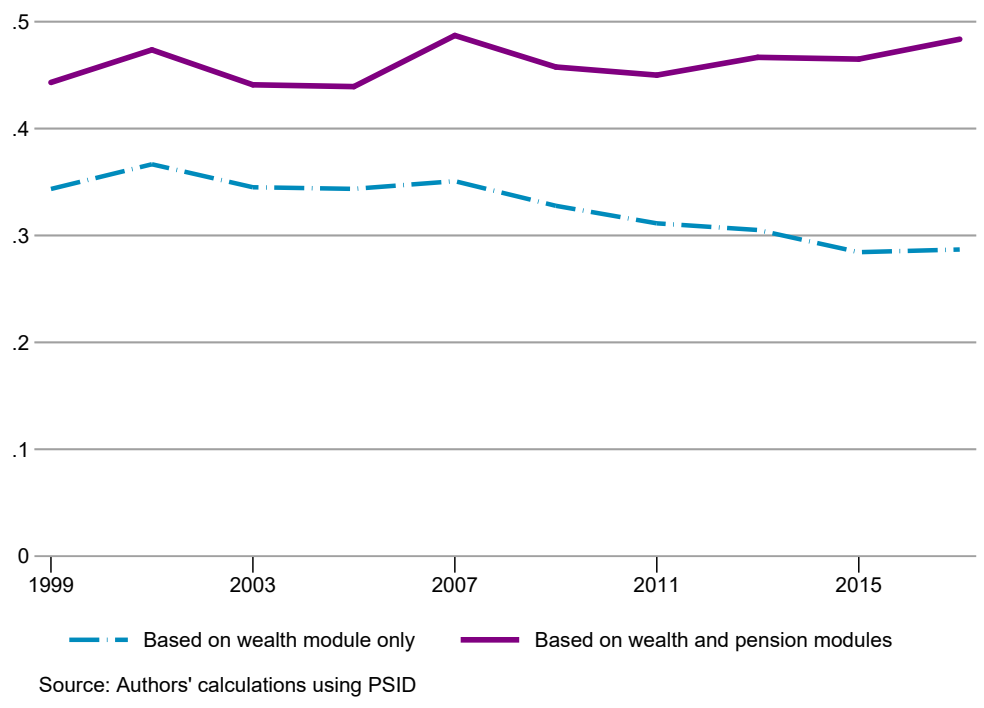

\section{Comparing PSID measures with SCF measures}

In this section, we provide some comparisons between the augmented PSID wealth measures and their SCF counterparts. The SCF is a triennial cross-sectional survey that began in its current form in 1989. The overall survey consists of a representative sample of US households as well as an oversample of wealthy households based on information from IRS tax records (Bricker, Henriques, and Moore 2017). With the release of each SCF, the Federal Reserve Bulletin publishes a report describing recent changes in US family finances ${ }^{19}$ The variables used for these reports-

\footnotetext{
${ }^{18} \mathrm{We}$ count a household as participating in the stock market if their reported (or estimated) value of stock market holdings is greater than zero.

${ }^{19}$ See, for example, Bricker et al. (2017).
} 
which capture information on household net worth, income, retirement assets, and other aspects of households' finances_can be downloaded from the SCF website. The website also includes an SAS program for generating the summary variables used for the Bulletin article as well as a flowchart linking the different variables, so that users can better understand which information from the survey underlies the reported statistics. ${ }^{20}$ The SCF summary measure of wealth is the “NETWORTH” variable, which equals households' financial plus nonfinancial assets less any debt. Among other things, financial assets (FIN) include liquid retirement assets (RETQLIQ), which equal the value of households' IRA/Keogh accounts (IRAKH) and DC pension accounts (THRIFT + FUTPEN + CURRPEN) ${ }^{21}$ The SCF has detailed questions about households' DC retirement accounts, including ones about how they are invested.

For both data sources, we aim to capture statistics that are representative of the US population. For the SCF, we use the provided sample weights that take into account the oversampling of wealthy households. For the PSID, we follow the approach in Fitzgerald, Gottschalk, and Moffitt (1998) and do not use weights and restrict our analysis to members of or descendants from the original, cross-sectional (representative) 1968 sample and exclude respondents who are from the poverty, Latino, and immigrant subsamples (the latter two were short-lived additions to the survey in the 1990s). This approach has been used in many PSID-based empirical studies, but an alternative approach would be to use the full PSID sample and apply weights to compute summary statistics. Our conclusions would be the same under this alternative approach, as the results are quite similar. (An example is offered below.)

We also align the unit of analysis across the two data sets. As Pfeffer et al. (2016) discuss, the SCF is at the household level, while the PSID is at the family level, which is not always equivalent to the household level. For example, an adult child who previously lived outside of his/her parents home but has moved back into the home would be treated as a separate family in the PSID, whereas in the SCF, the survey unit consists on an economically dominant individual or couple along with

\footnotetext{
${ }^{20}$ See https://www.federalreserve.gov/econres/files/bulletin.macro.txt and https://www.federalreserve.gov/econres/files/Networtho20Flowchart.pdf

${ }^{21}$ The Appendix contains more details regarding the NETWORTH variable in the SCF, including a more complete list of its components.
} 
all other individuals in the household who are financially interdependent. We follow the approach in Pfeffer et al. (2016) and aggregate across families within households in the PSID to make the unit of analysis fully comparable with the SCF. For the charts later in the paper that depict results for households in specific age ranges, we treat these combined households as being headed by the head with the highest reported wealth (economically dominant family). (In practice, we found that aligning the unit of analysis across data sets makes only small differences, but it does tend to make the PSID results slightly closer to the SCF results.)

\section{Overall wealth}

Figure 7 and Figure 8 show how the augmented PSID total wealth and financial wealth measures, respectively, compare with their SCF counterparts at different points in the wealth distribution. (Note the different vertical ranges.) The figures show that gaps are fairly small in recent years at the 50th and 75th percentiles for total wealth, and quite small in recent years at the 50th and 75 th percentiles of the financial wealth distribution. However, a substantial gap remains at the 25 th percentile for both total and financial wealth, even after we augment the PSID wealth measures with DC retirement account values. This result is unsurprising, given that few low-wealth households have DC accounts. At the 90th percentile, augmenting the reported PSID wealth measures closes only about half of the gap ${ }^{22}$ This result is also unsurprising, given that many high-wealth households have other types of assets that could be under-measured in the PSID ${ }^{23}$ (We obtain very similar results if we use the full sample of PSID households along with the sample weights—see Figure A4 in the Appendix for a comparison of the financial wealth data).

\footnotetext{
${ }^{22}$ The degree to which the gaps are closed can be seen in Figure 2 (for the 50th percentile) and in the first three graphs in the Appendix (for the other percentiles).

${ }^{23}$ The remaining gaps between the SCF and PSID wealth data, particularly at the 90th percentile, could result from a couple of factors. In particular, the SCF may be better at capturing households' assets, including pension assets, than the PSID is. The SCF also tracks assets—-such as households' business-related equity, managed investment accounts, and loans to other households-that the PSID does not try to capture.
} 
Figure 7: Comparisons of PSID and SCF Measures of Total Wealth
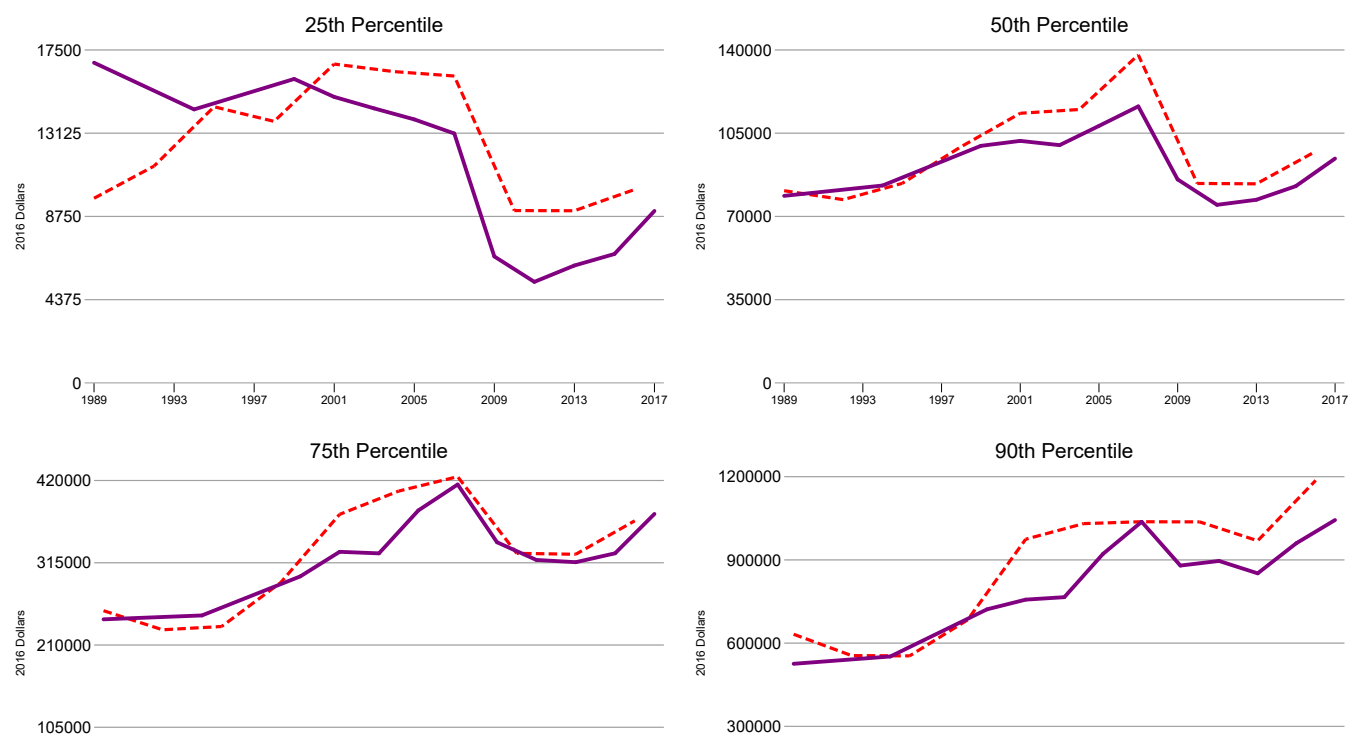

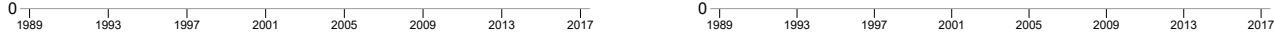

$$
\begin{aligned}
& \text { PSID Including DC Wealth = - SCF }
\end{aligned}
$$

Source: Authors' calculations using PSID, SCF

Figure 8: Comparisons of PSID and SCF Measures of Financial Wealth
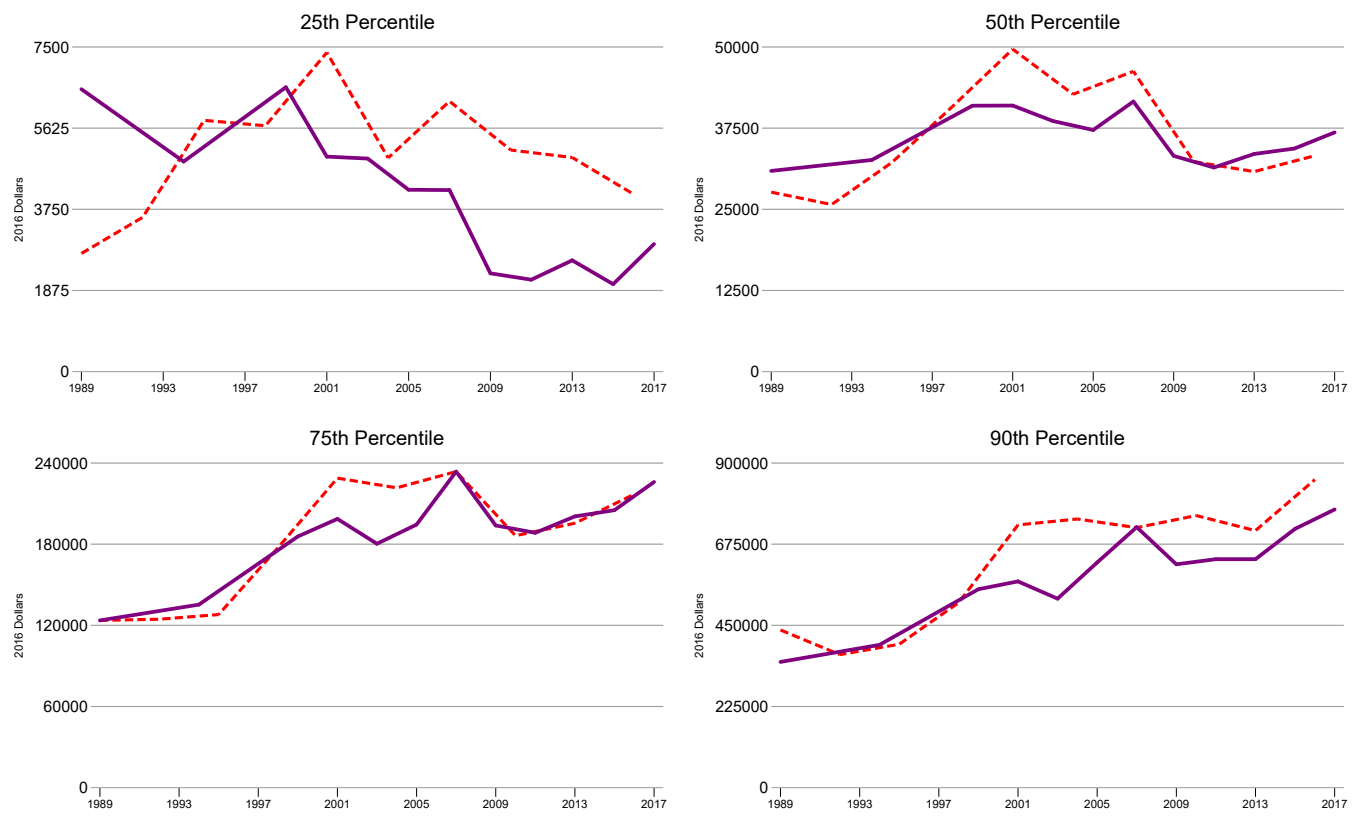

PSID Including DC Wealth = - SCF

Source: Authors' calculations using PSID, SCF Note: Financial wealth excludes home equity. 
Because we focus on retirement assets, we also look specifically at the wealth (retirement savings) of households approaching the age at which members typically retire. Having a good wealth measure is very important for evaluating the adequacy of these households' retirement savings. We consider households in two age groups: those whose household head is 45 to 54 years old and those whose head is 55 to 64 years old. Showing summary statistics for specific age ranges is helpful, because it allows us to abstract from population aging trends that can significantly influence overall wealth accumulation. Focusing on households who are in their late 40s, 50s, and early 60s is particularly useful in this context, because these households are in the years when they should be doing substantial saving for retirement (at least according to traditional life-cycle models of consumption). In keeping with many analyses of retirement saving, we focus on measures of wealth relative to income ${ }^{24}$ We stick with these age-group and wealth-ratio conventions for the remainder of our analysis.

Figure 9 compares the standard SCF wealth measure with the PSID measure that augments reported net worth with DC account values from the pension module. The median augmented wealth-to-income ratios for the PSID are lower than their SCF counterparts, but the gaps are large mainly prior to 2007, when the range data were unavailable to impute DC account values in the PSID. The gaps are fairly small in recent waves. In addition, the patterns of wealth over time suggested by the two data sources continue to be similar, with the median household seeing a decline in wealth relative to income during the financial crisis and little recovery since ${ }^{25}$ Overall, the figure suggests that the augmented PSID wealth data yield good information for this type of retirement-related analysis for the period when missing values can be imputed (beginning in 2007) but that the augmented wealth measures for earlier waves should be used with caution.

\footnotetext{
${ }^{24}$ For the SCF data, we express wealth relative to households' "normal" income-a measure that tries to capture the part of households' income that is not affected by transitory shocks. The PSID does not include such an income measure, so we use the average of households' (pre-tax) income in the current and previous wave to try to smooth through transitory fluctuations. (In the PSID, household income covers the calendar year prior to the survey year.) For all graphs, we compute wealth relative to income at the household level and then take the median across households.

25 Dettling, Hsu, and Llanes (2018) present post-crisis patterns of accumulated wealth for working-age households that appear to tell a similar story.
} 
Figure 9: Median Wealth-to-Income Ratios for Households Approaching Retirement

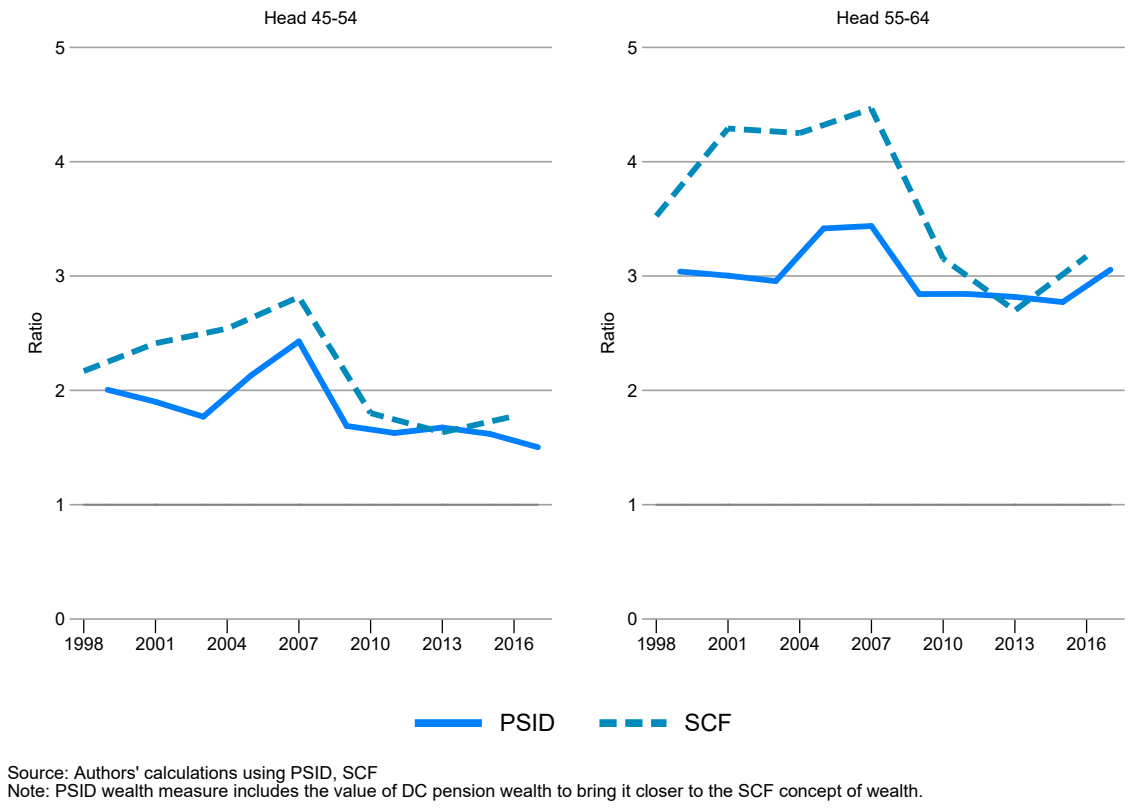

\section{Retirement Asset Data}

Focusing on assets that are specifically earmarked for retirement, we also compare the shares of households that report having some retirement account assets across data sets. Figure 10 plots the share of households with IRAs and DC accounts for PSID and SCF households 26 The reported shares of households with IRAs show a downtrend since the early 2000s in both data sources, particularly for the younger of the two age groups. The levels of these series also align quite well. In comparison, the estimated shares of PSID households with DC accounts fall short of the estimated shares of SCF households by 5 to 10 percentage points. Still, the gaps for recent years have been at the low end of this range, and both surveys show a generally flat trend since the early

\footnotetext{
${ }^{26}$ To determine whether PSID households have DC (and/or DB) retirement plans, we use question P16 (P16/P86 for spouses), which asks households about the type of retirement plan(s) they are eligible for through their current employer, and P46 (P46/P116 for spouses), which asks about accounts from previous employers. The options are DB, DC, or "both." We count households who respond "both" as having a DB and a DC plan. In addition, since DC plan eligibility does not imply participation, we require that the member, the employer, or both must be contributing to the plan for the household member to be counted as having a DC plan at his/her current employer. We count households as having an IRA if they report positive IRA assets. We count SCF households as having DC accounts or IRAs if they report positive values for these accounts ((THRIFT + FUTPEN + CURRPEN) $>0$ or IRAKH $>0)$, respectively. To assess whether SCF households have DB plans, we use the variable DBPLANT.
} 
Figure 10: Shares of Households with IRAs and DC Accounts
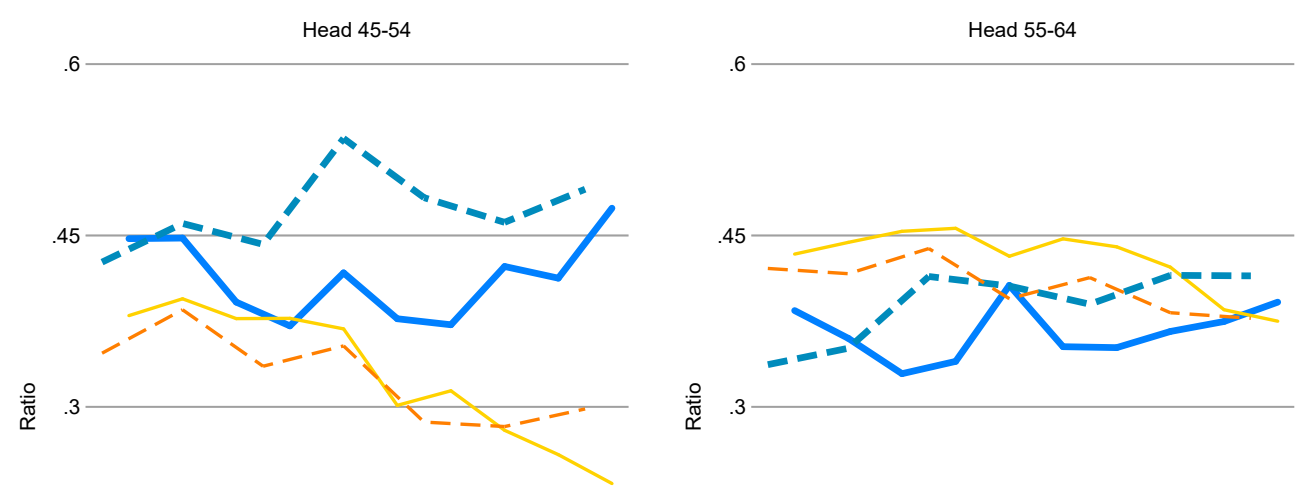

.15
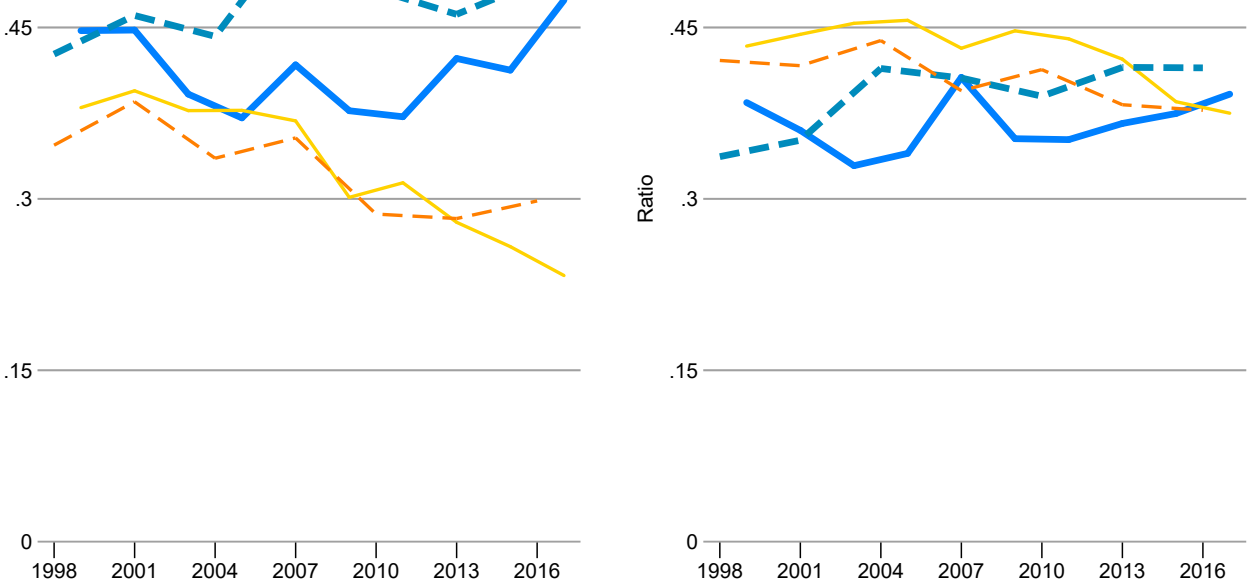

PSID: DC

PSID: IRA

SCF: DC

--- SCF: IRA

Source: Authors' calculations using PSID, SCF

Figure 11 shows the estimated shares of households that have either a DC account or an IRA (or both) from the two surveys. Combining information about the two different types of accounts may make sense in many contexts, both because they serve similar purposes for households in terms of financing retirement and because households may confuse the two types of accounts when responding to interviewers ${ }^{28}$ Although the shares for PSID households with a head aged 45 to 54 are a bit lower ( 3 to 6 percentage points) in recent years, the results on the whole are fairly similar. The results suggest that even though the PSID may not correctly report the split between households' types of retirement accounts (IRA versus DC), it does a fairly good job of capturing the overall share of households with retirement assets.

\footnotetext{
${ }^{27}$ The figures start in the late 1990s, because detailed retirement account data are not available in the PSID before that point.

${ }^{28}$ We do not suggest combining the information in all contexts. DC accounts have different properties-for example, being funded (typically) by automatic contributions from an employee's paycheck. In addition, looking at DC accounts separately would be helpful in an analysis of how the retirement benefits provided by employers are changing over time for households with different traits and experiences.
} 
Figure 11: Shares of Households with a DC Account, an IRA, or Both
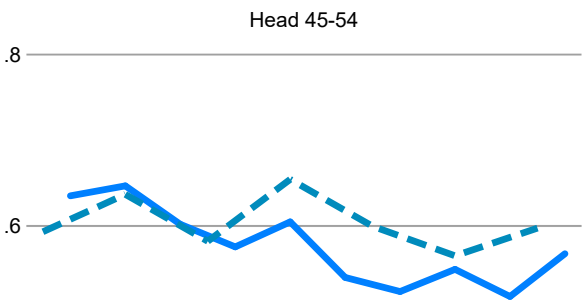

$$
\stackrel{\circ}{\stackrel{0}{\pi}}
$$

.2

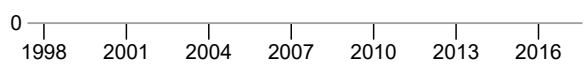

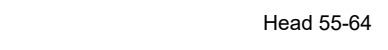

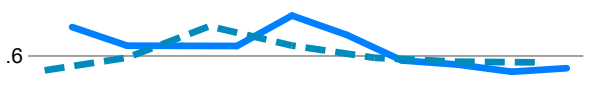

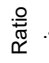

$$
.2
$$

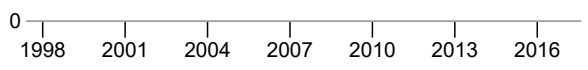

PSID $=-m$ SCF

Source: Authors' calculations using PSID, SCF

Turning to the reported amount of assets in these retirement accounts, Figure 12 plots the medians of the combined value of DC accounts and IRAs (relative to income) for the PSID and SCF for households who have DC and/or IRA accounts. ${ }^{29}$ The medians for the two surveys are remarkably close, with the data showing an uptrend in retirement asset values relative to income that sharpens in recent years (perhaps reflecting in part the booming stock market), especially for the older age group 30

\footnotetext{
${ }^{29}$ Figure A5 in the Appendix shows conditional medians of the value of DC accounts only. The results are quite similar.

${ }^{30}$ The PSID data extend through 2017, so they include the effects of an additional year of stock market strength relative to the data from the SCF, for which the last reading is for 2016.
} 
Figure 12: Median Combined IRA and DC Assets Relative to Income for Households with Positive Combined Assets

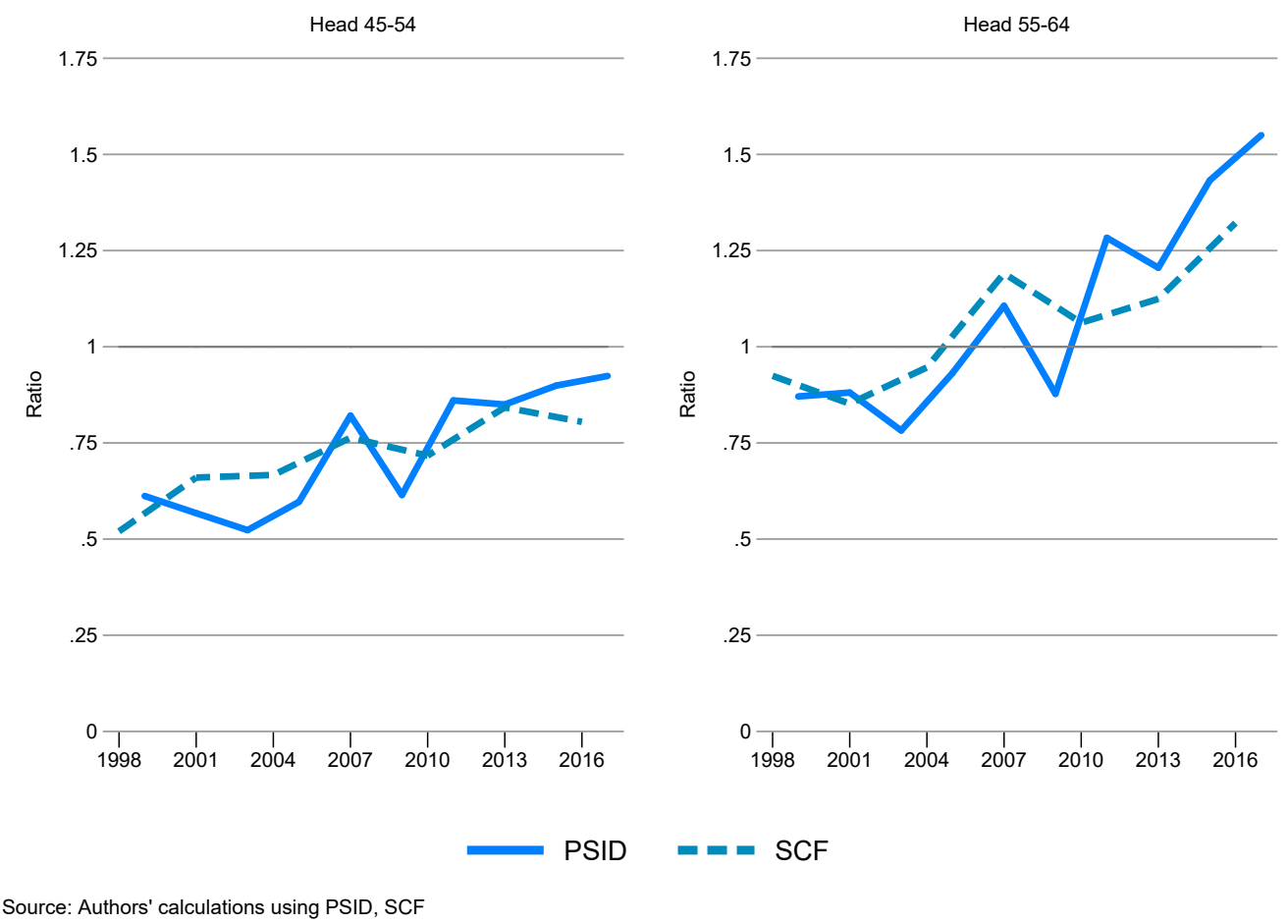

Of course, wealth accumulated through IRAs and DC accounts is not the only factor influencing households' retirement security. Another important factor for many retired households is income from private DB retirement plans. While we do not attempt to estimate the wealth that households in the two surveys have effectively accumulated through these plans, we explore how well the readily available information about whether households are covered by such plans compares. Figure 13 shows shares of PSID and SCF households who report having some coverage by a DB plan (or plans). Both surveys show a pronounced downtrend in DB coverage over time for both age groups. However, the PSID shares are somewhat lower than the SCF shares for most years. In addition, we are unsure why the PSID shares for the older age group show a much sharper decline than the SCF shares in the early 2010s. The PSID made some changes to related questions in the pension module in the 2011 wave, but the changes do not appear to have directly affected the questions that we used to derive these series (PSID 2013). 
Figure 13: Shares of Households Reporting Some Coverage by DB Pension Plans
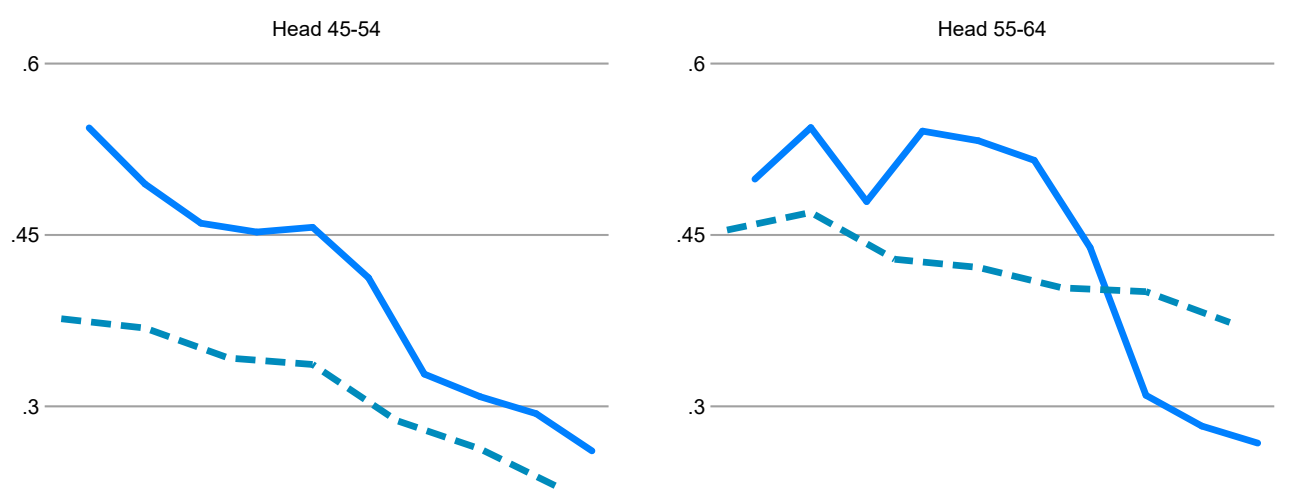

.15

15

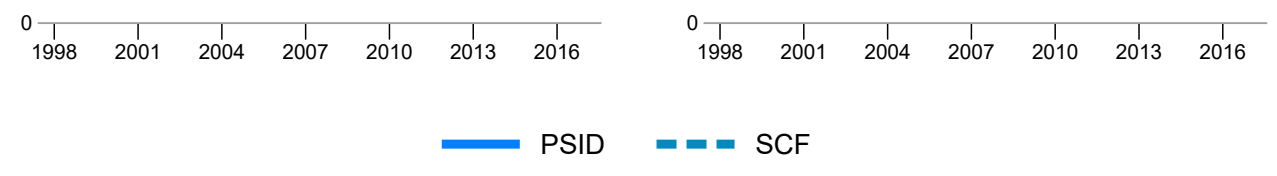

Source: Authors' calculations using PSID, SCF

Finally, we look at how estimates of the shares of households participating in the stock market based on the augmented PSID wealth data compare with the implied shares based on the SCF data. As shown in Figure 14, the PSID implies a somewhat lower stock market participation share for the two age groups, compared with the SCF. However, the time-series patterns are similar, with stock-holding among households trending slightly downward in recent years. 
Figure 14: Share of Households Participating in the Stock Market
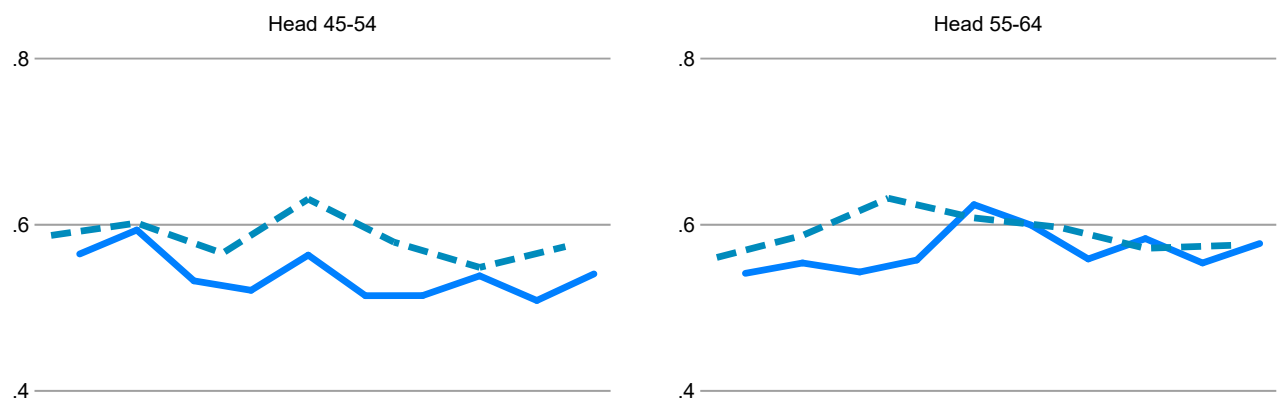

.2
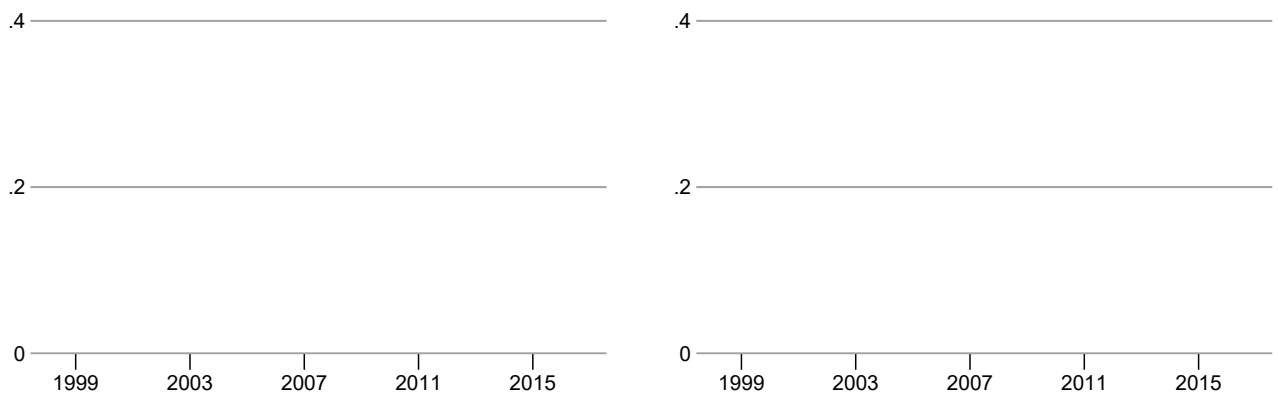

PSID $=-\operatorname{SCF}$

Source: Authors' calculations using PSID, SCF Note: PSID share based on wealth and pension modules.

To sum up, while there are clearly some gaps, we think the retirement asset information that can be drawn from the PSID pension module stands up fairly well against comparable measures from the SCF. While we have some reservations about the data collected before the 2007 wave, due to our inability to impute data for households who report having DC accounts but do not know the amount in their accounts, the results suggest we can be reasonably confident about the data from the 2007 wave onward. Given the significant rise in the importance of DC accounts to the balance sheet of the typical household in recent decades, we think that researchers interested in household retirement security should use these PSID pension-module-based data. Likewise, we believe that, compared with the data derived from the PSID wealth module alone, the overall augmented measure of household wealth in the PSID that we describe in Section 2 provides a markedly clearer picture of the financial security of the typical household. 


\section{How Research Can Be Enhanced by these Measures}

There are many contexts in which the PSID workplace retirement saving account data and augmented household wealth measures discussed in this paper might be important for research. In this section, we highlight three specific examples.

First, these data can enhance the study of household retirement security. Many papers that examine the likely future retirement security of working-age households use the SCF due to the excellent quality of its information about accumulated wealth (see, for example, Gale, Gelfond, and Fichtner 2019; Pang and Warshawsky 2014). However, as a cross-sectional survey, the SCF provides only a snapshot of any given household. Consequently, it cannot be used to study how events over a household's working life affect the accumulation of wealth for retirement. In contrast, the rich longitudinal data in the PSID can be used to explore the relationship between life-cycle saving and factors such as job history, spending shocks, and family-structure changes ${ }^{31}$ Yet, such studies can be done well only if the data from the PSID wealth module are augmented with the DC account data from the PSID pension module, so that the analysis captures the full scope of the financial assets potentially held by households.

Second, these data can help us better understand the effects of recessions on households. Assets accumulated through workplace retirement saving accounts may help households weather recessions and idiosyncratic hard spells. Indeed, more than half of unemployed respondents to a 2010 survey by Pew reported that they had withdrawn money from a retirement account to pay their bills (Morin and Kochlar 2010). Some households are also able to borrow against their retirement accounts in times of hardship. The DC account data from the PSID pension module in combination with the PSID's information about job history and spending changes should allow researchers to better understand the degree to which retirement account assets can be used for consumption smoothing 32 Of course, using retirement saving in this way can compromise a household's fi-

\footnotetext{
${ }^{31}$ The Health and Retirement Study is another rich longitudinal data set that is often used to study retirement security issues. However, it covers only individuals who are over the age of 50, and, with only limited data on individuals' experiences over their working lives, it is less useful for understanding how older households accumulated their wealth.

${ }^{32}$ In related work, Bridges and Stafford (2019) explore the factors that motivate households to withdraw money from their retirement plans.
} 
nancial security later in life, if the savings are not replenished in better times. Indeed, studying whether households are able to replenish their retirement accounts after drawing them down would contribute to the literature on the scarring effects of recessions.

Third, these data are important for any analysis of how households change their consumption in response to changes in capital gains on stocks. The robust correlation between the stock market and consumption in the aggregate (at least until recently) has been well documented, but less is known about the underpinnings of the relationship at the household level. To study this question, one needs data that capture both households' holdings of stocks and their spending; the data must also have a panel dimension so that wealth changes and capital gains can be calculated. The PSID wealth module's information about stock holdings does not include stocks held in workplace retirement saving accounts. As a result, using only the data from the wealth module could lead to biased estimates of the marginal propensity to consume (MPC) out of stock market gains ${ }^{33}$ In separate research, we are exploring such stock market wealth effects by incorporating information from the PSID pension module; we are also looking at whether households have a different response to capital gains on assets that are explicitly earmarked for retirement (perhaps due to their lesser liquidity or because of mental accounting behavior) 34

These three examples are just a subset of the research areas where a more comprehensive measure of wealth in the PSID would be useful. Such measures are relevant to papers exploring macroeconomic models with heterogeneous agents, research on how retirement assets bear on health and disability outcomes, and studies of wealth inequality ${ }^{35}$ More generally, we think that

\footnotetext{
${ }^{33}$ The sign of the bias is ambiguous. Using only wealth module information ignores the behavior of households who are exposed to the stock market only through their DC accounts, which could attenuate the measured effect if the ignored households have higher MPCs. At the same time, households holding stocks outside of their DC accounts are very likely to also be holding stocks in their DC accounts. This could potentially lead to upward bias, since household spending would be responding to actual capital gains that are larger than the measured capital gains. There is also the potential for measurement error in households' reported stock (and DC) account values.

${ }^{34}$ Households are also exposed to the stock market, to some degree, if they have defined-benefit (DB) pension plans that have invested in the stock market; the main exposure is that the plan might not be able to pay the promised benefits if returns are very low. We doubt that most households understand this exposure, so we do not view DB wealth as an important component of the study of wealth effects at the household level.

${ }^{35}$ Of course, there is a trade-off related to the more limited period for which the augmented wealth series is available, particularly given the caveats about the pre-2007 data. Studies that focus on wealth trends all the way back to the early 1980s or consider the intergenerational transmission of wealth inequality might be better served by using the traditional PSID summary wealth data to maintain a consistent wealth measure over time.
} 
researchers conducting a PSID-based study of outcomes that might be influenced by household economic security should consider using the augmented wealth measure that we have described in this paper, instead of measures based on the information from the PSID wealth module alone. Although the different measures are correlated at the household level, wealth held through DC accounts has come to represent a large portion of the financial wealth held by many middle-income households. Given this shift, many types of analysis would be enhanced by using a broader measure of wealth. 


\section{References}

Bosworth, Barry, and Rosanna Smart. 2010. "Evaluating Micro-Survey Estimates of Wealth and Saving." https://papers.ssrn.com/sol3/papers.cfm?abstract_id=1368830

Bricker, Jesse, Lisa Dettling, Alice Henriques, Joanne Hsu, Lindsay Jacobs, Kavin Moore, Sarah Pack, John Sabelhaus, Jeffrey Thompson, and Richard Windle. 2017. "Changes in U.S. Family Finances from 2013 to 2016: Evidence from the Survey of Consumer Finances." Federal Reserve Bulletin 103(3).

Bricker, Jesse, Alice Henriques, and Kevin Moore. 2017. "Updates to the Sampling of Wealthy Families in the Survey of Consumer Finances.” Finance and Economics Discussion Series 2017114. Board of Governors of the Federal Reserve System. https://doi.org/10.17016/ FEDS.2017.114

Bridges, Thomas P., and Frank P. Stafford. 2019. "Pre-Retirement Pension Saving: Responses to Liquidity Change and Consumption."

Dettling, Lisa, Joanne Hsu, and Elizabeth Llanes. 2018. “A Wealthless Recovery? Asset Ownership and the Uneven Recovery from the Great Recession." FEDS Notes. Board of Governors of the Federal Reserve System. September 13, 2018. https://doi.org/10.17016/23807172.2249

Fitzgerald, John, Peter Gottschalk, and Robert Moffitt. 1998. "An Analysis of Sample Attrition in Panel Data: The Michigan Panel Study of Income Dynamics." The Journal of Human Resources 33(2): 251-99.

Gale, William, Hilary Gelfond, and Jason Fichtner. 2019. "How Will Retirement Saving Change by 2050? Prospects for the Millennial Generation.” Peter G. Peterson Foundation US 2050 Working Paper. https://www.pgpf.org/us-2050/research-projects/ How-Will-Retirement-Saving-Change-By-2050-Prospects-for-theMillennial-Generation 
Morin, Rich, and Rakesh Kochlar. 2010. "The Impact of Long-term Unemployment: Lost Income, Lost Friends-and Loss of Self-respect." Pew Research Center Social Demographic Trends Report. https://www.pewresearch.org/wp-content/uploads/sites/ 3/2010/11/760-recession.pdf

Pang, Gaobo, and Mark Warshawsky. 2014. "Retirement Savings Adequacy of U.S. Workers." Benefits Quarterly 30(1): 29-38.

Pfeffer, Fabian T., Robert Schoeni, Arthur Kennickell, and Patricia Andreski. 2016. "Measuring Wealth and Wealth Inequality." Journal of Economic and Social Measurement 41(2): 103-120.

PSID. 2013. "PSID Main Interview User Manual: Release 2013." https:// psidonline.isr.umich.edu/data/Documentation/UserGuide2011.pdf

Sabelhaus, John, and Alice Henriques Volz. 2019. "Are Disappearing Employer Pensions Contributing to Rising Wealth Inequality?" FEDS Notes. Board of Governors of the Federal Reserve System. February 1, 2019. https://doi.org/10.17016/2380-7172.2308 


\section{A Appendix}

\section{A.1 Measuring Wealth in the PSID and SCF}

\section{PSID}

The PSID wealth supplements include data on eight components of household wealth as well as summary variables for total household net worth (with and without housing equity) where missing data are assigned. Wealth data are available in the PSID in 1984, 1989, 1994, and then in every wave starting in 1999. Information on homeowners' housing equity (self-reported house values less self-reported mortgage debt) is available in every wave.

As an example, the PSID mnemonics for the nine wealth components, which can be summed to create a (nonimputed) measure of household wealth (with or without housing equity), are the following in the 2017 wave:

- Housing equity (ER66031 - (ER66051 + ER66072))

- Other real estate (ER67776 - ER67780)

- Business (ER67789 - ER67793)

- Stock (ER67798)

- Bonds (ER67847)

- Vehicles (ER67784)

- IRAs (ER67819)

- Cash (ER67826)

- Other debt (ER67852 + ER67862 + ER67867 + ER67872 + ER67877 + ER67883)

The PSID also includes constructed summary wealth measures, which it labels "WEALTH1" (without housing equity) and "WEALTH2" (with housing equity). In the 2017 wave, the PSID data documentation describes "WEALTH2" as follows.

"WEALTH2": Constructed wealth variable including (housing) equity. This imputed variable is constructed as the sum of values of seven asset types (ER71429 [farm/business, W11A], 
ER71435 [cash, W28], ER71439 [other real estate, W2A], ER71445 [stocks, W16], ER71447 [vehicles, W6], ER71451 [other assets, W34], ER71455 [IRA/annuity, W22]) net of the sum of non-primary housing debt (ER71431 [farm/business, W11B], ER71441 [other real estate, W2B], ER71459 [credit card, W39A], ER71463 [student loan, W39B1], ER71467 [medical, W39B2], ER71471 [legal, W39B3], ER71475 [family loan, W39B4], ER71479 [other, W38B7]) plus the value of home equity (ER71481). All missing data were assigned.

\section{SCF}

The SCF contains more detailed wealth data than the PSID does. However, these data are combined into broader categories that are similar to those available in the PSID. The summary household wealth measure in the SCF, which is labeled "NETWORTH," equals household assets less any household liabilities, and it includes housing equity.

The main components of household wealth in the SCF are 36

- Non-financial assets (NFIN)

- Housing equity (HOUSES)

- Other real estate (ORESRE+NNRESRE)

- Business (BUS)

- Vehicles (VEHIC)

- Other (OTHNFIN)

- Financial assets (FIN)

- Liquid assets (LIQ)

- Certificates of deposit (CDS)

- Directly held pooled investment funds (NMMF)

- Directly held stocks (STOCKS)

- Directly held bonds (BOND)

\footnotetext{
${ }^{36}$ This information and more details on the NETWORTH variable in the SCF are available in this flowchart on the SCF website: https://www.federalreserve.gov/econres/files/Networtho20Flowchart.pdf
} 
- Savings bonds (SAVBND)

- Cash value of life insurance (CASHLI)

- Other managed assets (OTHMA)

- Quasi-liquid retirement assets (RETQLIQ)

* IRAs/Keoghs (IRAKH)

* DC plans from current job (THRIFT)

* DC plans from previous employers

- currently receiving (CURRPEN)

- not yet receiving (FUTPEN)

- Other (OTHFIN)

- Debt (DEBT=MRTHEL+RESDBT+OTHLOC+CCBAL+INSTALL+ODEBT)

\section{A.2 Additional Figures}

Figure A1: Comparisons of PSID and SCF Measures of Wealth: 25th Percentile
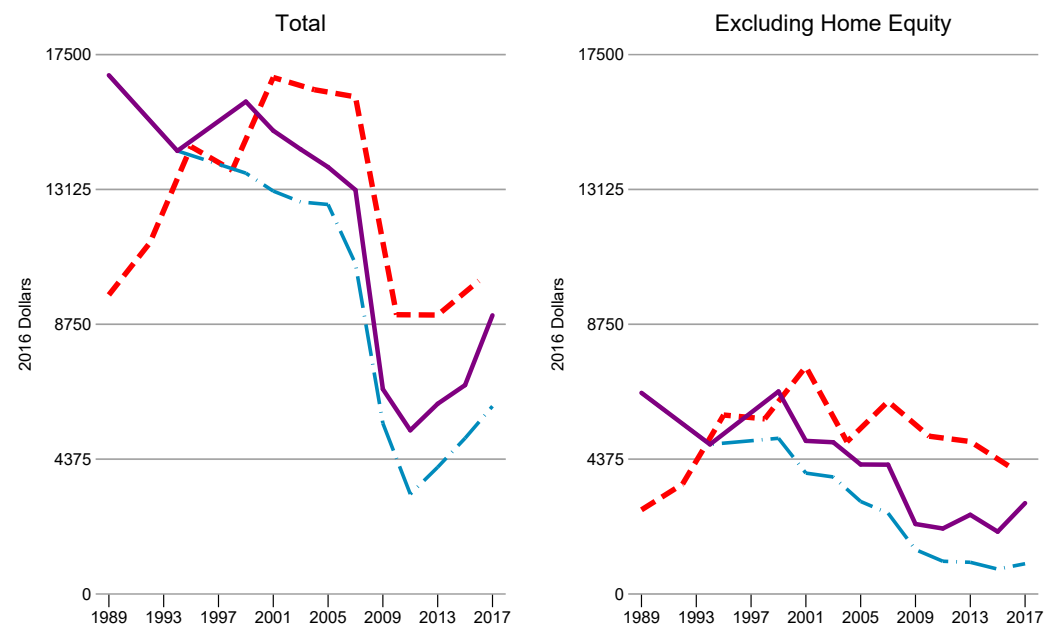

- - PSID PSID Including DC Wealth

$=-=$ SCF 
Figure A2: Comparisons of PSID and SCF Measures of Wealth: 75th Percentile
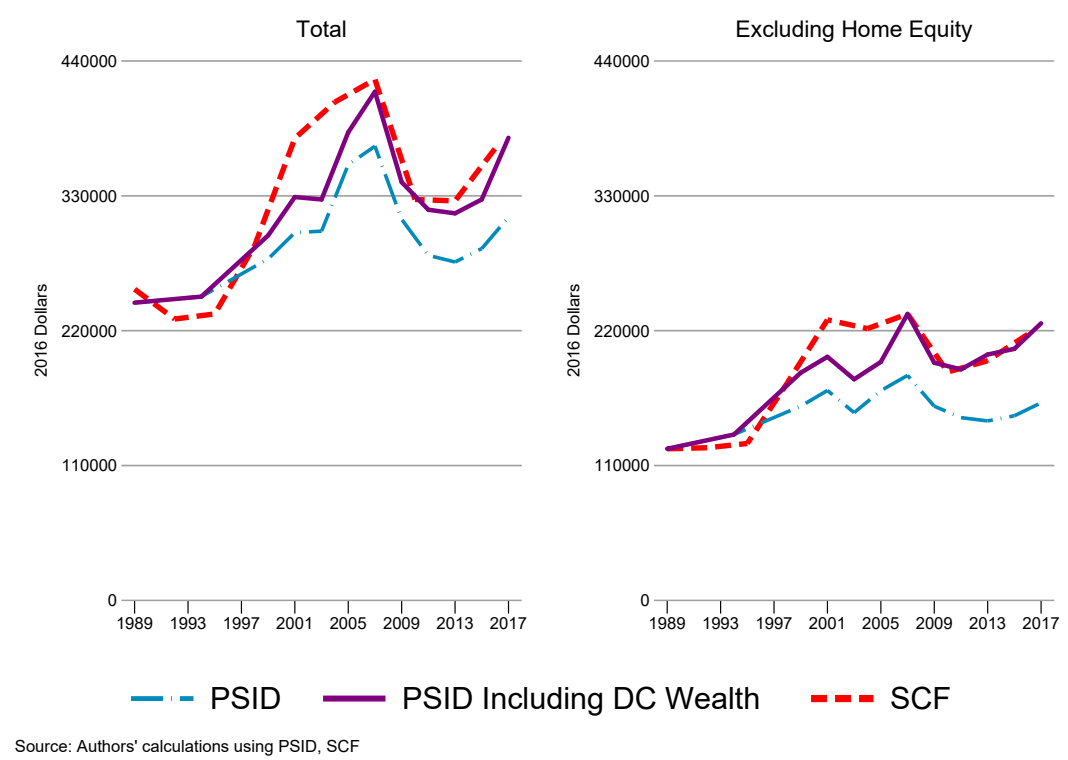

Figure A3: Comparisons of PSID and SCF Measures of Wealth: 90th Percentile
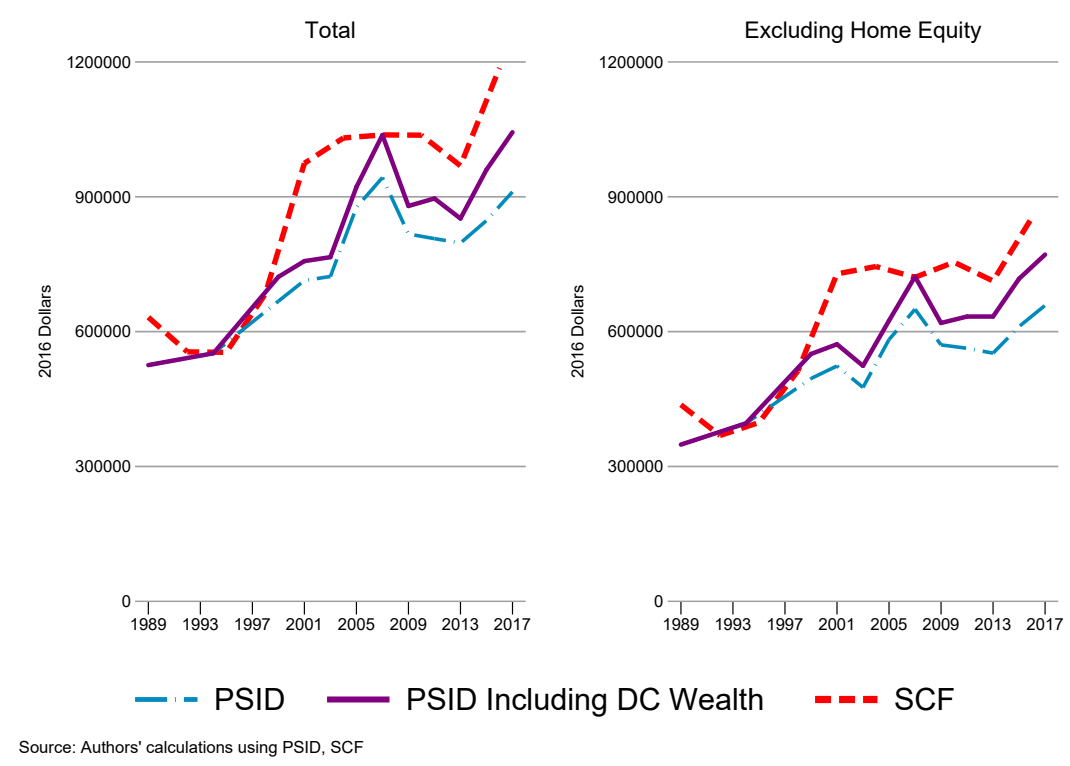
Figure A4: Comparisons of PSID and SCF Measures of Financial Wealth

Full Sample of PSID Households (with Weights)
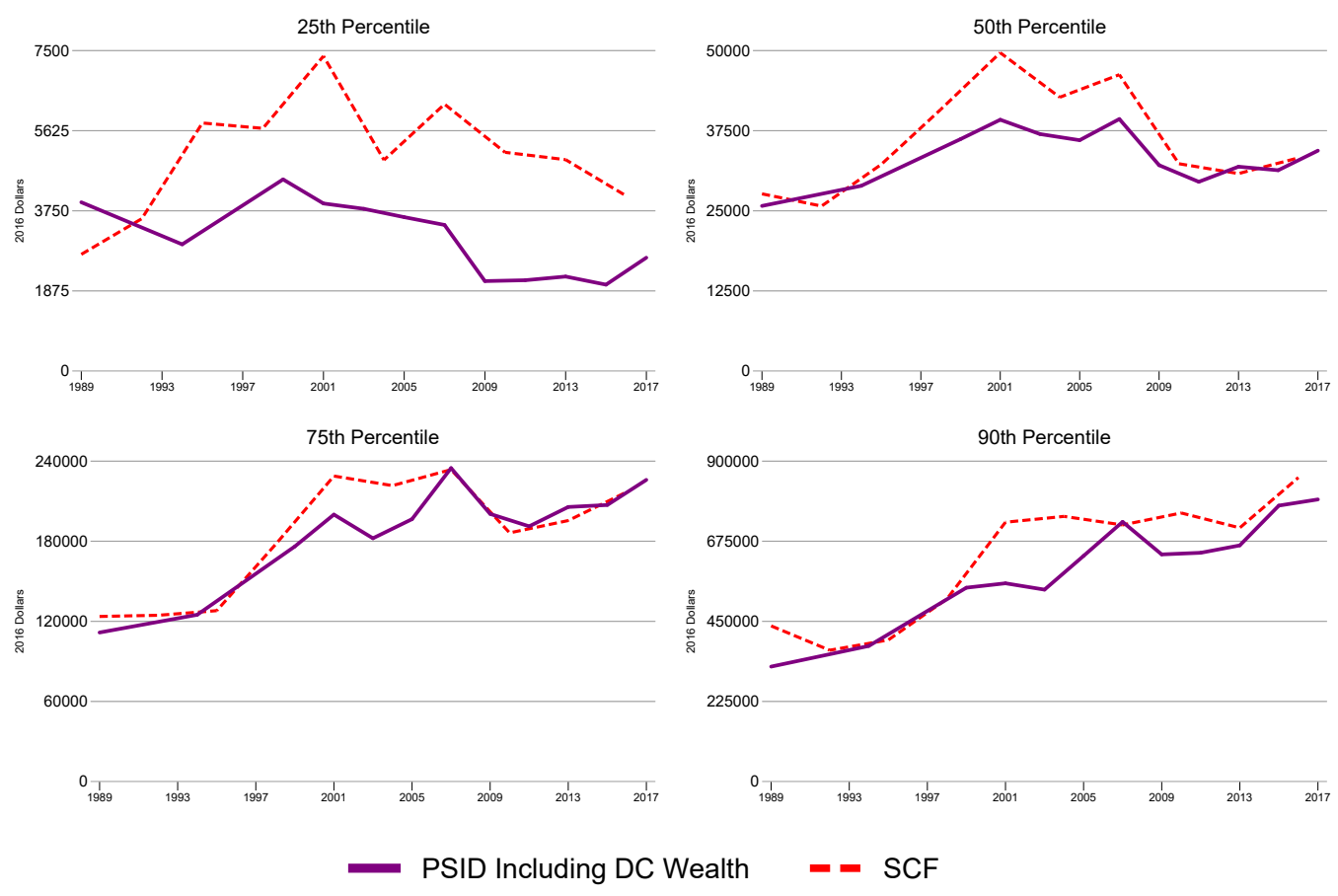

Source: Authors' calculations using PSID, SCF Note: Financial wealth excludes home equity.

Figure A5: Median Ratios of DC Assets to Income for Households with Positive DC Assets

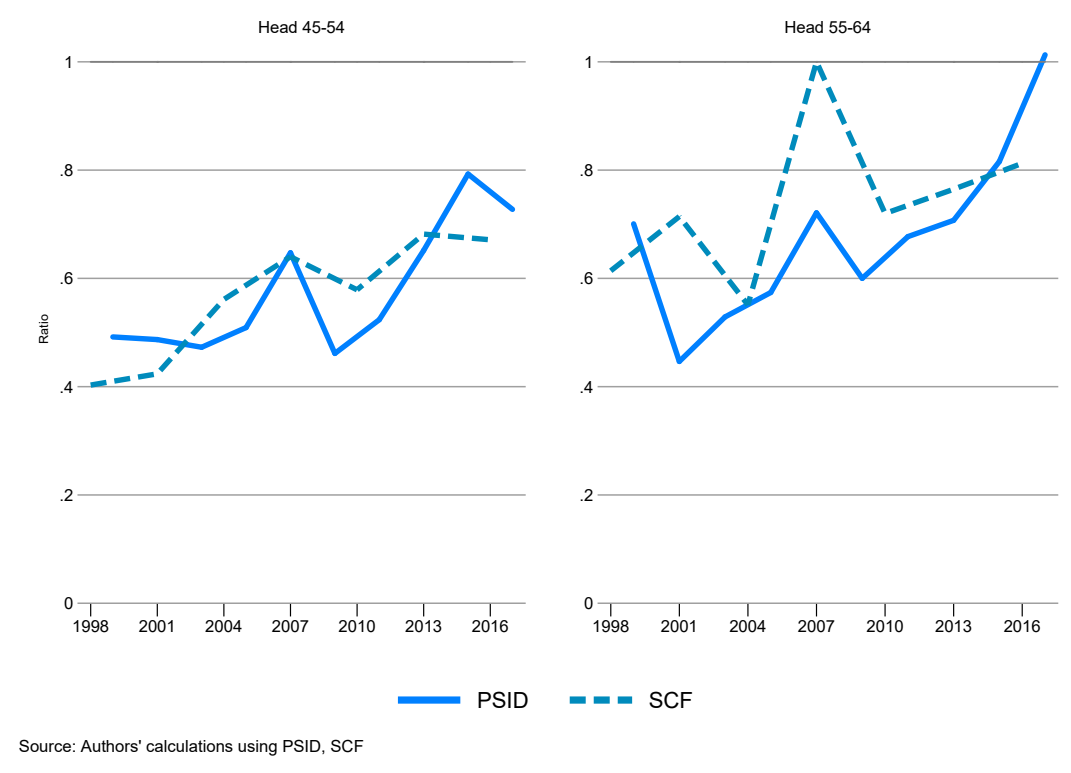

